\title{
Form, Science, and Narrative in the Anthropocene
}

\author{
Marco Caracciolo ${ }^{1}$
}

Ghent University

marco.caracciolo@ugent.be

Rev. August 28, 2018

Please cite print article in Narrative 27 (3): 270-89 (October 2019).

\section{Keywords}

Nonhuman, New Formalism, Science and literature, Scale, Metaphor, Plot

\section{Abstract}

A significant strand of contemporary fiction engages with scientific models that highlight a constitutive interdependency between humanity and material realities such as the climate or the geological history of our planet. This article looks at the ways in which narrative may capture this human-nonhuman interrelation, which occupies the foreground of debates on the so-called Anthropocene. I argue that the formal dimension of scientific knowledge-as manifested by diagrams or metaphors used by scientists-is central to this narrative remediation. I explore two analogical strategies through which narrative may pursue a formal dialogue with science: clusters of metaphorical language and the global structuring of the plot. Rivka Galchen's novel Atmospheric Disturbances (2008), for instance, builds on a visual representation of meteorological patterns in a storm (lifted from an actual scientific paper) to stage the narrator's mental illness. Two other contemporary works (Orfeo by

\footnotetext{
${ }^{1}$ The author's work on this article was supported by the European Research Council, grant number 714166 (NARMESH).
} 
Richard Powers and A Tale for the Time Being by Ruth Ozeki) integrate scientific models through the overall design of the plot. By offering close readings of these novels, I seek to expand work in the area of New Formalism and show how formal choices are crucial to bringing together the human-scale world and more-than-human phenomena.

\section{Introduction}

As an avant-garde composer, Peter Els, the protagonist of Richard Powers's 2014 novel Orfeo, is no stranger to artistic experimentation. One of the most striking musical experiments we read about in the novel involves "soundtracks extracted from DNA-strange murmurings transposed from the notorious four-letter alphabet of nucleotides into the twelve pitches of the chromatic scale" (333). Invisible genetic material is thus made tangible through sound. But Peter's intuition, which sparks the novel's plot, is that this translation can be reversed:

The real art would be to reverse the process, to inscribe a piece for safekeeping into the genetic material of a bacterium. The precise sounds that he inscribed into the living cell were almost immaterial: birdsong, a threnody, the raw noise of this arboretum, music spun from the brain that those self-replicating patterns had led to, four billion years on. Here was the one durable medium, one that might give any piece a shot at surviving until alien archaeologists came by to determine what had happened to the wasted Earth. (333)

By encoding music in genetic patterns, Peter is looking for a ground, a "durable medium," for art that would transcend the spatiotemporal strictures of the human species: the limitations of our visual perception, which keep humans from directly experiencing genetic structure; 
but also the posthuman temporality of the "wasted Earth" observed by alien archeologists. Whether seen in spatial or in temporal terms, Peter's art attempts to supersede the reassuring "intermediate world" of embodied experience, to borrow a term from ecological psychologist J. J. Gibson (22): the human-scale reality to which our perceptual and cognitive apparatus is attuned. Peter's art, as the quotation spells out, is an art of "pattern," or more accurately of bridging between patterns: it connects the sensible structure of music to the insensible structure of genetic material, the double helix of DNA. What Peter realizes, however, is that the directionality of this process is in itself meaningful. In "soundtracks extracted from DNA," invisible patterns are scaled upwards, made sensible. In his DNA compositions, the sensible patterns of music are made invisible: the result, as Peter puts it, is "wild forms and fresh sonorities. Tunes for forever, for no one" (299).

Powers's novel highlights the coming together of formal patterns at different spatial scales, as well as the divergent directionality implicit in movement across those scales: the upwards displacement (from the microscopic to the human-scale) of sounds extracted from DNA, the downwards displacement of composing music in DNA form. The problematics of scale is not new to literary studies, and to the humanities more generally; in fact, scale has been discussed extensively in recent ecocritical debates on the so-called Anthropocene, from Derek Woods's "scale critique" to Timothy Clark's "scale effects." With the accumulation of scientific evidence for the ecological and climatological impact of industrial activity (through pollution and the emission of greenhouse gases, for instance), the mutual dependency of human societies and the environment has become increasingly clear (see Crutzen; Chakrabarty). Therefore, the human scale is revealed to be fundamentally entangled with phenomena that elude direct perception and can only be conceptualized through scientific experimentation and modeling; these "nonhuman" realities-to borrow the term 
popularized by Richard Grusin in an influential collection-include entities and processes of vastly different magnitude, from DNA and $\mathrm{CO} 2$ molecules to large-scale meteorological patterns.

This article seeks to bring into focus the specific contribution of narrative form to the imagination of nonhuman scales. As Timothy Morton notes, the field of ecocriticism "has overlooked the way in which all art-not just explicitly ecological art-hardwires the environment into its form" (11). While Morton's comment, from his 2010 The Ecological Thought, is no longer completely accurate today, much remains to be done to marry ecocritical concerns and discussions on literary and narrative form. This is one of the core tasks of what Erin James calls an "econarratology." My goal in this article is to show that narrative can engage with the nonhuman realities investigated by science along two dimensions, both of which-like Peter's art-foreground pattern: clusters of related metaphors, at the micro-textual level; and the structural organization of plot at the macrolevel.

The common denominator between these formal strategies is analogy. Whether it is realized in the linguistic device of metaphor or in larger plot patterns, analogy becomes the site of conversion between different spatiotemporal scales: it brings out continuities and unsettling ruptures between the intermediate world and other levels of reality. Often, analogy reveals human-nonhuman entanglements by breaking down - that is, by failing to fully capture scales beyond the human, a shortcoming that creates distinctive emotional effects in the audience. I will thus explore how formal patterns in narrative can contribute, both locally and globally, to the patterning of audiences' narrative experiences. This contribution is modulated by forms derived from sensory perception (cognitive linguists call them "image 
schemata"), which determine the overall affective "shape" of plot. This is the more speculative side of my argument, but it is crucial to raise the point that form is never merely a textual "given," since it always ripples within each reader's experience of narrative. Together with clusters of metaphorical language, the image schemata that structure plot create a formal possibility-again, based on analogy - for the narrative assimilation of scientific models. I will exemplify these ideas by offering close readings of three contemporary novels: along with Powers's Orfeo, Rivka Galchen's Atmospheric Disturbances and Ruth Ozeki's A Tale for the Time Being, the latter of which will be the subject of an extended reading at the end of the article.

Before turning to those examples, however, I will elaborate on the claim that contemporary narrative and scientific models of more-than-human realities can find a common ground in form. I will build on Caroline Levine's version of New Formalism to contextualize my claim that the form of narrative is capacious enough to accommodate forms that exist well below, or far above, the intermediate world of human perception.

\section{Abstraction Techniques: Science and Form}

In Forms, a landmark contribution to a scholarly movement known as New Formalism (see Levinson), Caroline Levine focuses on how the forms of political or social action intersect with aesthetic form. This is made possible by a broad definition of form as "all shapes and configurations, all ordering principles, all patterns of repetition and difference" (3). In a reading of Elizabeth Barrett Browning's poem "The Young Queen," for instance, Levine (7381) explores the interplay between poetic rhythm (i.e., meter and prosody) and the rhythms imposed by the social order, showing how the former can implicate and at the same time resist the latter. Narrative takes center stage in Levine's account; she claims that stories are 
particularly well equipped to capture "the experience of colliding forms .... Narratives are valuable heuristic forms, then, because they can set in motion multiple social forms and track them as they cooperate, come into conflict, and overlap, without positing an ultimate cause" (19). Put otherwise, narrative form is able to subsume a variety of socio-cultural forms.

Levine's account can be extended by considering how science itself produces a wide range of forms, which enter the domain of culture at large. Just as narrative can assimilate and challenge forms of institutional control and political power, it can interact in complex ways with the forms of science. What does it mean to apply the label "form" to science? At one level, formalization in science is a matter of abstraction: from a welter of data points, scientists extrapolate a model that expresses the relevant features or trends underlying the data. This movement towards a general law can certainly be called an act of formalization. But it is important to understand how this kind of abstraction is bound up with devices that are "formal" in a sense closer to the aesthetic meaning of the term. Philosopher of science Nancy Nersessian (11) identifies four "abstraction techniques" that scientists use as they develop and revise scientific models. Particularly promising, from my perspective in this article, are the first two techniques: (1) analogical reasoning and (2) imagistic reasoning. Under the heading of "analogical reasoning," Nersessian discusses the role of analogical thinking in science: analogy draws attention to continuities and discontinuities between levels of reality (see also a seminal collection edited by Ortony). Nersessian's argument turns on James Clerk Maxwell's notion of electromagnetic field, but I will discuss an alternative example from $19^{\text {th }}$ century science, which I find more illuminating than Nersessian's: namely, Charles Darwin's famous analogy between artificial selection and natural evolution in On the 
Origin of Species. Darwin observes how pigeons are selectively bred by humans to display specific physical features; he builds on this idea, analogically, to understand how natural evolution operates on animal species, by selecting traits that improve an organism's chances for reproduction. Yet the analogy is imperfect: as Darwin puts it, "man can act only on external and visible characters: Nature ... cares nothing for appearances, except in so far as they may be useful to any being" (56). Even more crucially, natural selection is not driven by human intentionality and agency in the same way as artificial selection. Indeed, for Nersessian, it is when analogy breaks down that it is at its most useful, because the modifications required by an analogy to fit a given data set are a step towards a new theory. Physical representations, such as diagrams or other forms of data visualization, facilitate this process of abstraction; this is what Nersessian calls "imagistic reasoning." She points out that such images "provide an intermediate level of abstraction between phenomena and mathematical forms of representation (formulae)" (25). Diagrams are human-scale equivalents of processes that cannot be observed directly; unlike purely mental images, they stabilize a phenomenon in a way that frees up cognitive resources in the scientist and potentially enables further inferences. A case in point is Darwin's tree of life diagram in On the Origin of Species-a visual representation of the more-than-human temporality of speciation by way of natural selection. Darwin's "I think" on top of a preliminary version of the tree of life in his notebooks (see Figure 1) is a further demonstration of the integral role of diagrammatic representation in the development of scientific models. 


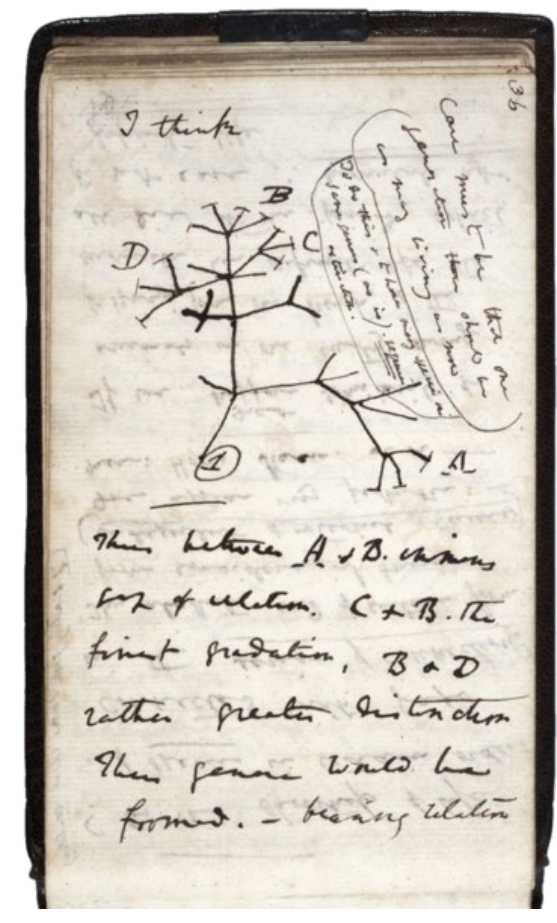

Figure 1 An early version of the tree of life diagram, from Charles Darwin's notebooks. Copyright Cambridge University Library (https://www.amnh.org/exhibitions/darwin/the-idea-takes-shape/i-think/).

The formalism of science is thus not just a matter of inference-the movement to a higher level of generality, through statistical or mathematical models; it has to do with the conceptual and sensory forms that are employed by scientists in the process of knowledge formation and communication: conceptual forms, through analogy (and "tree of life" is in itself based on analogy, of course); and sensory forms, through visual models.

If we define scientific formalism along these lines, an opportunity of dialogue between narrative and science will come into view. Powers's Orfeo, discussed in the introduction, offers an intriguing demonstration of this dialogue by blending the diagrammatic form of DNA - the iconic double helix - with its two interlaced plot lines. As my analysis below will detail, the first plot line focuses on the events of Peter's biography up to the realization that the genetic material of a bacterium, Serratia marcescens, could serve as a ghostly musical score. The second plot line relates the events triggered by an FBI investigation into Peter's 
activities; the FBI misrepresent his musical experimentations, leading to charges of bioterrorism and precipitating Peter's clumsy and ill-fated attempt to escape arrest.

It is a fairly common narrative device to weave together two separate plot lines. But in the context of Powers's novel this device is revitalized by being conflated with the scientific form that the novel foregrounds in thematic terms: namely, the double helix of DNA. Readers are thus cued to use the helix as an imagistic form to understand, analogically, Powers's plot design. In this way, the shape of narrative crystallizes and negotiates the form of more-thanhuman realities. Similar devices are employed in a wide range of contemporary novels that, through an engagement with science, convey a sense of humanity's entanglement with nonhuman realities. Adam Trexler discusses some of these novels under the heading of "Anthropocene fiction." In the next section I will turn to a specific example of how the dialogue between narrative and scientific models plays out in Anthropocene novels. This analysis will enable me to expand on the role that analogical and imagistic reasoning play in bridging narrative form and scientific abstraction, via metaphor and image schemata.

\section{Metaphor, Directionality, and a Model Storm}

Rivka Galchen's novel Atmospheric Disturbances (2008) centers on a character who suffers from a psychiatric condition known as Capgras syndrome: he considers his wife an impostor, a lookalike of his real wife. In his delusion, the narrator believes that his wife's "disappearance" is part of a broader conspiracy devised by the Royal Academy of Meteorology-an institution devoted to "maintaining weather's elements of unpredictability and randomness" (12). The weather thus plays a central role in the plot, implicating broader anxieties related to climate change and the unpredictability of its consequences. Particularly significant is the narrator's misrepresentation of a diagram originally intended as a model of 
wind speed and temperature inside a storm (see Figure 2). This diagram is lifted from an actual scientific paper (Hane et al.) and reprinted in Galchen's novel; it is, thus, a literal remediation of a scientific model in a narrative context.

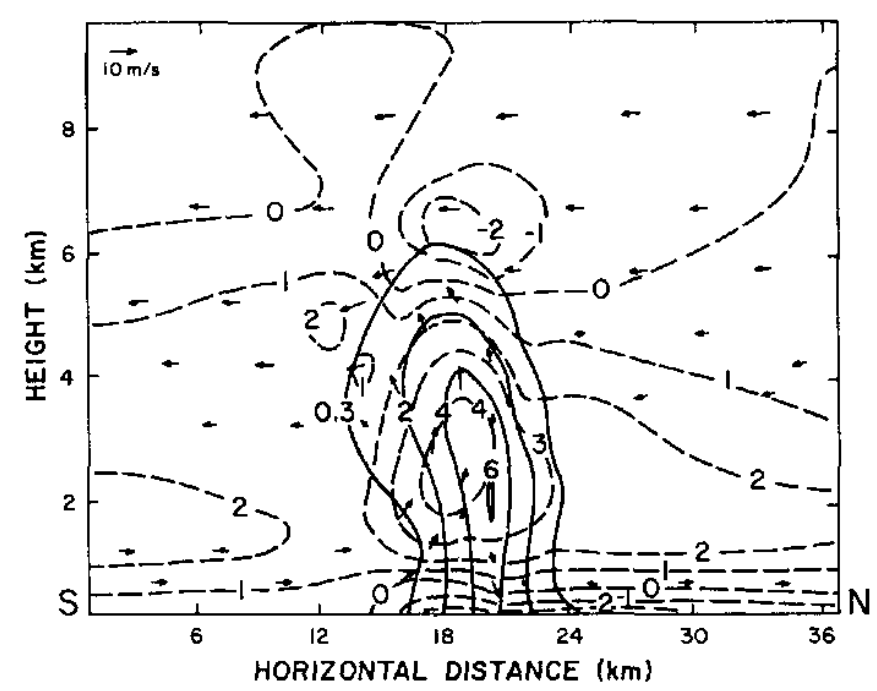

Figure 2 A diagrammatic representation of a storm, from Atmospheric Disturbances (Galchen 59).

The narrator observes this diagram, neglects its intended function as a visual representation of meteorological processes, and confesses: “I'm unable to reproduce the effect, the effect the image had on me, which was, well, uncanny, like those dolls whose eyes seem to follow you around a room. Like I was looking at a topographical map of a landscape I knew only from close up. Some sense of concordance, and meaning, of a pattern both inscrutable and yet, at some almost cellular level, detected" (59). At first, the narrator anthropomorphizes this image: he compares the hypnotic effects of looking at the central figure to the uncanniness of dolls. Then scale comes to the fore, in another simile that performs a movement towards a higher level of abstraction: this is no longer a human-scale, if disquieting, object but a "topographical map." And, finally, a sense of patterning emerges, bound up with an unspecified but deeply affective meaning. 
The narrator misunderstands the formalism of science and transposes it into an emotional pattern, with the metaphorical language - the similes-doing most of the work of sewing together the intermediate world of embodied perception and the diagrammatic representation. Even more productive in narrative terms is the clash between what we know the diagram is supposed to represent and what the narrator reads into it. Nersessian's point about analogy in scientific discovery can be extended to literary narrative: analogy is at its most meaningful when it falls short, pointing up tensions and discontinuities between the source and the target domain. This includes the verbal manifestation of analogy in metaphor and simile. In the passage from Galchen's novel, the metaphorical language displaces a scientific model into a lived experience that is deeply affecting, for the narrator, and incongruous, for the reader. Indeed, the unreliability of Galchen's narrator is more likely to prove estranging than bonding (to use James Phelan's terminology; see Phelan, "Estranging Unreliability"): anecdotally, my experience teaching Atmospheric Disturbances suggests that readers have trouble relating to Galchen's narrator and understanding his motives, which creates a sense of puzzled distance in reading the novel.

Clusters of metaphorical expressions (including both similes and metaphors proper) can become a form - that is, to quote again Levine's definition, a "pattern of repetition and difference" - that interacts with other formal or thematic dimensions of a story. In particular, such analogical patterns are crucial to the scale work that narrative must perform as it brings together human-scale and nonhuman realities (see also Caracciolo et al. for a more systematic, empirically oriented demonstration). Here the directionality of metaphor comes into play. Simply put, it is not the same to say "the visual representation of a storm looks like a doll" and "a doll looks like the visual representation of a storm." The source and target domains of these similes may be the same, but they are not interchangeable. In 
Gestalt terms, it is a question of figure and ground: in the first statement, what occupies the foreground of readers' attention (the figure) is a doll; in the second, it is the visual representation of a storm. While in the first statement the figure is human-scale and directly perceptible, it is not in the second: "a doll looks like the visual representation of a storm" involves a much higher degree of abstraction, because it seeks to understand something concrete in terms of something far more intangible and scientifically mediated. This is not the preferred option in everyday metaphor: in the wake of George Lakoff and Mark Johnson's work, one of the tenets of cognitive linguistics is that metaphor tends to bring down abstract concepts to human-scale experience-a view known as "experientialism" (see Rohrer).

Elena Semino explicates this idea as follows: "Cognitive metaphor theorists emphasize that target domains typically correspond to areas of experience that are relatively abstract, complex, unfamiliar, subjective or poorly delineated, such as time, emotion, life or death. In contrast, source domains typically correspond to concrete, simple, familiar, physical and well-delineated experiences, such as motion, bodily phenomena, physical objects and so on" (6). This tendency is reversed in the statement "a doll looks like the visual representation of a storm," where the target domain (the doll) is concrete, while the source domain (the visual representation of a storm) is a scientific model of a weather phenomenon. Linguistically and conceptually, then, "a doll looks like the visual representation of a storm" is thus a more creative and counterintuitive choice, because it resists the pull of embodied experience and moves in a direction opposite to experientialism: by using an abstract structure as source domain, it brings out the nonhuman within what is apparently human-scale. This is an example of how mappings involving the same semantic elements can display opposite directionalities. 
The concept of directionality can be extended to whole narratives: when a certain metaphor or set of related metaphors underlie a novel (as in Powers's Orfeo, with its mapping between DNA structure and the interlaced story lines), directionality determines the specifics of the interaction between narrative and the formal models that it seeks to remediate. In Stories, Meaning, and Experience, Yanna Popova offers an insightful account of the relationship between narrative and metaphor; her argument is that, in general, the causal structuring of narrative takes precedence over the analogical structuring of metaphors in a narrative context: "It is more appropriate to say that the meaning of metaphors is functional with respect to the plot, not that metaphorical structuring takes over the narrative" (114). Yet metaphor and narrative, Popova adds, can interact in two ways: in the case of allegory, a whole narrative serves as the source domain of a metaphorical expression whose target domain is not spelled out but strongly implied (for instance, The Pilgrim's Progress as an allegory of Christian life). Alternatively, clusters of semantically related metaphors and similes can make "specific contributions to the causal structuring of a story" (113). In Popova's examples, the short stories "The Beast in the Jungle" and "The Figure in the Carpet" by Henry James, "the main narrative action is interspersed by the regular appearance of a central metaphor that articulates the narrative goal not explicitly but indirectly" (114).

Powers's novel offers a particularly clear-cut case of a central metaphor, which the plot literalizes: for Peter Els, music is not just like DNA structure, it can be physically composed in DNA form. In Galchen's novel, the literalization occurs mostly at the local level: a scientific diagram becomes an image that hovers between the mimetic (a doll) and the abstract (a model of weather patterns), eliciting a powerful affective response in the narrator. This reading of the diagram thus creates linkage between two semantic domains: human 
psychology and the weather. The analogy feeds into the plot via the narrator's mental illness: through his involvement with the Royal Academy of Meteorology, he develops an obsession with the weather. Here is, for instance, how he uses a meteorological simile to discuss a happy period in his marriage: "we had a sweet space of time, like the Medieval Warm Period, when wine grapes could grow three hundred miles farther north than they do today" (17). Human relationships are scaled upwards, being equated with periodic variations in the climate and with their impact on human activity (such as viticulture).

The directionality of these metaphorical mappings marks an important difference, though. In Powers's novel, if we accept my reading, the central metaphor pushes away from the human-scale world: Orfeo suggests that the intermediate world of human experience may be controlled by an invisible, bacterial world. As we read in the novel: "all the standard accounts of human affairs turned comical and self-serving. Trade, technology, nations, migrations, industry: the whole drama was really being orchestrated by Earth's five nonillion mutating microbes" (193). The formal patterning of Atmospheric Disturbances is more complex, in that the upwards directionality of individual metaphors (such as that of the Medieval Warm Period) is counterbalanced by the sharp focus on the narrator's psychiatric condition: from that perspective, more-than-human weather phenomena are brought down to the human scale, providing a lens to understand the vagaries of the narrator's mind (see Fortin). Yet it is equally possible to read the narrator's mental illness as an allegory for the human species' collective madness as it fails to pay sufficient attention to the climate and rushes towards a planetary disaster.

The directionality of the novels' analogical systems points to different ways in which narrative may negotiate the divide between everyday experience and scientific models. As 
already discussed, the shortcomings of an analogy are often more meaningful than the analogy itself: they suggest that movement from one level of reality to another is not always smooth and unproblematic (see also Woods). This is precisely the challenge raised by the Anthropocene: the spatiotemporal scales involved in scientific models of-for instanceclimate change cannot be easily collapsed into the scale of human, everyday experience, and vice versa.

The novels I discussed so far register this trouble with scale in ethical and affective terms. Peter Els's genetic manipulation of bacteria for artistic purposes is in equal parts brilliant and controversial. As Jim Holt writes in a New York Times review, the "DNA in any organism . . . is a knowledge-bearing structure, a sort of poem composed by time and chance. To alter even a bit of it for would-be artistic purposes is tantamount to aesthetic vandalism-like spraying a graffiti message on the Parthenon" (Holt). For its part, Atmospheric Disturbances explores the mental illness of a narrator who sees the world in terms of the weather, with incongruous effects as readers come to terms with his unreliability. The next two sections turn to another "pattern of repetition and difference" in narrative-the level of organization that is commonly known as plot-to show how the form of plot can also become analogically bound up with nonhuman realities. We'll see that, along with analogy, imagistic reasoning (i.e., reasoning through sensory form) plays a key role at this level.

\section{Image Schemata and the Shape of Plot}

As Karin Kukkonen points out, "plot" is a multifaceted concept that refers to both the global structure of narrative and to its "progressive structuration" as readers work out "the connections between story events, motivations and consequences" (Kukkonen, para.4). It is the latter, more dynamic perspective on plot that interests me here, because it 
demonstrates how narrative form is never exclusively a matter of textual strategies but involves a dynamic structuring of readers' experience.

Arguably, the focus on experiential effects was already present in Aristotle's Poetics and has become central to more recent accounts of plot, including those offered by rhetorical theories of narrative (Booth; Phelan, Experiencing Fiction). Also from the viewpoint of cognitive approaches, there is a growing consensus that plot is closely related to emotional dynamics in the audience (Tan; Hogan). Philosopher David Velleman, for instance, argues: "The cadence that makes for a story is that of the arousal and resolution of affect, a pattern that is biologically programmed. Hence we understand stories viscerally, with our bodies" (13). Velleman's cadence represents, of course, a very broad perspective on narrative dynamics, but we can refine this concept by distinguishing between different kinds of emotional patterning in narrative. Data scientist Andrew Reagan and his collaborators have studied these emotional dynamics through the lens of a "big data" approach (Reagan et al.). They fed a large corpus of written narratives into a computer algorithm capable of so-called sentiment analysis, which enabled them to plot the affective trajectory of each story-to plot the plot, so to speak-by identifying emotional patterns in language. Their conclusion was that narratives fall into six basic "emotional arcs," in their terminology, depending on the progression of the text's emotional valence: "rags to riches" stories, for example, show a gradual and constant rise in emotional tone (increasingly positive emotions), while Cinderella-like stories display a rise followed by a fall (more negative emotions), culminating in a final rise-the happy ending.

These emotional arcs are thus strongly aligned with generic categories, as Hogan's affective narratology posits in a more theoretical vein. However, due to methodological limitations in 
Reagan et al.'s big data approach, their account of plot patterns remains tied to a simplified view of emotional language, whereby affect only fluctuates along a positive-negative axis. An alternative-and more nuanced-account is offered by a cognitive linguist, Michael Kimmel, who conceptualizes the affective patterning of plot in terms of image schemata. Popularized by Lakoff and Johnson at the end of the 1980s, the concept of image schema has its roots in Gestalt psychology: an image schema is a formal pattern that is derived from perception but commonly extended to the conceptual domain in a variety of linguistic contexts (for further discussion on image schemata, see Grady). Vyvyan Evans and Melanie Green (190) have drawn up a comprehensive inventory of image schemata. PATH and BALANCE are textbook examples: we first experience motion along a path or balance in the physical domain, in our own bodies, but we leverage these concepts to think and talk about relatively abstract things, such as the passage of time or someone's mental stability. (I will follow the cognitivelinguistic convention of capitalizing image schemata below.)

Kimmel argues that image schemata are central to readers' understanding of narrative as well, and not just in the trivial sense that plot is often conceptualized as a PATH leading from a narrative beginning to an ending. Rather, the tensions that set a plot in motion as well as the protagonist's goals and fortunes create-in Kimmel's term-a certain "affective contour," which readers follow by drawing on their familiarity with basic, embodied image schemata. As Kimmel writes, "such image schemas can be sensed by readers, often in their bodies, as an arc of FORCE tension or denouement as reinstated BALANCE schema" (173). The rise and fall in positive emotions studied by Reagan et al. would thus be a single dimension of this affective patterning of plot, based on the image schemata UP and DOWN. But readers' affective experience of plot may be structured by schemata that are less genre- 
bound. The following is a partial list of image-schematic structures in narrative, geared towards my textual analyses in the following pages:

- As Marie-Laure Ryan has shown in chapter 7 of Possible Worlds, Artificial Intelligence, and Narrative Theory, the textual progression of narrative is usually tied to characters' desires and goals. When plot throws complications at the linear PATH of the protagonist's intentions, we have the BLOCKAGE image schema.

- BLOCKAGE may also be realized at the discourse level by way of digressions or flashbacks that have the effect of temporarily delaying the outcome of an action sequence.

- Narratives that combine multiple story lines create an impression of SUPERIMPOSITION, as if the strands of the plot were placed on top of one another spatially.

- The MERGING image schema is evoked whenever these story lines come together (e.g., with characters meeting or action sequences converging), in what Arnaud Schmitt would call a plot "knot."

- The LINK image schema involves a thematic or diegetic connection between story lines that remain distinct, corresponding to what Schmitt calls a "connector."

- The CYCLE image schema is triggered whenever narrative foregrounds plot patterns that are alternative to the PATH model, in that they implement a circular or loop-like logic.

Image schemata thus provide a language to conceptualize the formal dimension of plot, where the word "formal" has a double meaning: it denotes both the abstraction of moving from a concrete plot device to its underlying schematic structure, and the fact that image 
schemata have a sensory form or shape that is derived from embodied experience. The organization of plot can thus be seen as fundamentally imagistic, to use Nersessian's terminology.

Powers's interlaced story lines in Orfeo are a case in point. As I mentioned above, the novel juxtaposes two action sequences: a biographical narrative spanning from Peter's school years to his artistic maturity as an avant-garde composer; and Peter's predicament as he, much later in his life, attempts to evade arrest by fleeing across the U.S. following accusations of bioterrorism. Not only are these narrative threads separated by a temporal gap, but they are chronologically uneven: the former involves decades of Peter's life, the latter only a few days or weeks at most. Yet these story lines are equally stretched out in the course of the novel and intertwined via periodical flashbacks, which take the reader back to Peter's past. This structure results in a clear image-schematic organization: at one level, the forward movement of the bioterrorism story line (along a PATH image schema) creates suspense as to the character's fate; but this movement is obstructed-BLOCKAGE image schema-by the flashbacks, which heighten the suspense both by delaying the outcome of Peter's escape attempt and by strengthening readers' empathetic bond with him (in that background information on the protagonist puts us in a better position to understand him).

Only at the end of the novel do the story lines converge: the biographical narrative catches up with where the bioterrorism story line had started at the beginning of the novel; Peter, now a solitary retiree, admires "rhythms inscribed in the branching veins" of an oak leaf (330) and decides to embark on a new project, composing similar rhythms in DNA form: “Making things felt strange again, and dangerous. Patterns might yet set him free. That evening, he set to work ordering parts for a home laboratory" (334). As the novel 
foregrounds pattern at a diegetic and thematic level, the formal patterning of the plot itself emerges: the final pages mark a final MERGING of two story lines that the narrator had alternated throughout the novel一an effect that activates the SUPERIMPOSITION image schema. This ending results in a highly satisfying sense of pattern completion, which provides closure and enriches the forward-looking suspense that had sustained the reader's interest in Peter's life. Describing plot in terms of image schemata thus shows that textual strategies are closely aligned with the contour of readers' experience of narrative, which is at the same time affective and formal.

In Powers's Orfeo the image-schematic interlace of plot is not, of course, a purely arbitrary narrative design, but becomes fully justified at the diegetic level, in three consecutive analogical steps. The first step is the already discussed equation between DNA structure and musical composition: Peter's musical experimentations are made possible by the literalization of the analogy "music is like DNA structure." The second step involves an analogy between music and narrative organization. Even seemingly abstract, nonrepresentational music cannot but tell a story, as Peter realizes: "From the first leaping figure in the strings, Els heard again the problem with music. Even the slightest tune sounded like a story. Melody played on the brain like a weather report, an avowal of faith, gossip, a manifesto. The tale came across, clearer than words. But there was no tale" (280). The passage implies that music and narrative share an affective "substrate," as Ellen Dissanayake puts it: emotion structures our experience of both narrative and music, to the extent that music tends to take on narrative qualities as listeners inevitably read a story-like progression into its emotional patterning. Powers's novelistic art reverses the directionality of Peter's analogy: the typographically demarcated comments that occur throughout the novel (marking the transitions between story lines) serve as an equivalent of musical 
counterpoint, while the two story lines create an effect of polyphony. Through these formal devices, Powers invites readers to perceive not the narrativity of music (as in the passage just quoted) but the musicality of narrative itself.

The third analogical step brings together DNA and plot via the mediation of music: the novel's story lines become human-scale equivalents of the two strands of nucleic acid in DNA. This is an uneasy imagistic equivalence, of course, and tinged by Peter's awareness that the invisible world of DNA cannot be fully captured in human-scale form-a discontinuity between levels of reality that explains the defamiliarizing effect of his "tunes for forever, for no one" encoded in bacterial DNA. What allows the novel to establish a deep analogy between the sensory (music), the verbal (narrative, the novel), and the nonhuman is their fundamental patterning. This idea is brought out by one of the counterpoint-like comments that punctuate the novel: "There is another world, the world in full. But it's folded up inside this one" (202). The expression "folded up" has a strong image-schematic nature, associated with the SUPERIMPOSITION schema; here it serves two functions, alluding to the nonhuman scale of DNA but also, self-referentially, to how this comment is literally folded up inside the novel's narrative organization. Plot is thus linked, precariously but no less powerfully, to the scientific imagination of the nonhuman world. The linkage is formal, affective, and at the same time conceptual, articulating a vision of how humanity itself is "folded up" in a fundamentally more-than-human world. In the next section, I turn to another Anthropocene novel-Ruth Ozeki's A Tale for the Time Being, to further exemplify the interaction between plot structure and scientific models; we'll see that Ozeki's novel adopts a distinctive image-schematic form: not Powers's SUPERIMPOSITION and eventual MERGING, but a logic that combines CYCLE and LINKAGE. 


\section{Stories Like Geodrift: A Tale for the Time Being}

In a pivotal scene of $A$ Tale for the Time Being, Oliver explains to Ruth, his wife, the phenomenon of ocean gyres, large systems of currents that flow through the Earth's oceans. Ruth is the author's fictional alter ego, an American writer living on a remote island off the coast of British Columbia, and one of the novel's two protagonists. As Oliver discusses the gyres, his body physically performs their vortex-like movement: “'Imagine the Pacific,' Oliver said. 'The Turtle Gyre goes clockwise, and the Aleut Gyre goes counterclockwise.' His hands moved in the great arcs and spirals of the ocean's flow" (13). Oliver's gestures offer an embodied equivalent for a concept growing out of scientific research in oceanographyanother analogical attempt to translate the nonhuman into human-scale language. He continues: "Each gyre orbits at its own speed .... And the length of an orbit is called a tone. Isn't that beautiful? Like the music of the spheres. The longest orbital period is thirteen years, which establishes the fundamental tone. The Turtle Gyre has a half tone of six and a half years. The Aleut Gyre, a quarter tone of three. The flotsam that rides the gyres is called drift. Drift that stays in the orbit of the gyre is considered to be part of the gyre memory" (13-14). Oliver develops a musical analogy (the "tone") that is closely reminiscent of Powers's DNA score in Orfeo. Astronomical language ("orbits," "music of the spheres") enriches the gyre-music analogy, reversing the directionality of his previous embodied performance: Oliver's gestures brought the gyres down to the human scale, while the cosmic hints in this passage scale them up to astronomical magnitude.

Despite these dramatic shifts, Oliver's analogies converge on an image schema of CYCLE or circular movement; they dematerialize reality, sublimating it into an abstract pattern. This effect continues in the second half of the quotation, with the progression flotsam $>$ drift $>$ 
memory. Scientific jargon here infiltrates Oliver's explanation, determining a gradual loss of substance of the wreckage dragged along by the gyres: an increasing abstraction that results in the metaphorical ascription of a mental function to the gyres. "Ocean memory" is a conventional metaphor in oceanography; it is used to discuss the way in which large bodies of water retain traces of past climatological trends: for instance, environmental scientists Chris Old and Keith Haines write that the "persistence of volume (heat) anomalies is equivalent to the ocean's memory of warming or cooling climatic events" (1144). Just as Galchen's narrator misrepresents a meteorological model, Ozeki turns a scientific metaphor into the premise of the plot: the novel can be read as an attempt to convey the imagistic patterning of "gyre memory" through narrative form.

Thematically, A Tale for the Time Being offers an intriguing combination of Zen Buddhism, quantum mechanics, and environmental philosophy. This cultural eclecticism reflects the fact that the plot straddles the Pacific, with chapters focused on characters located on both sides of the ocean: Nao, a Japanese teenage girl who experiences vicious bullying at school as she comes to terms with proximal and distal family history-including the legacy of her grandmother, a Buddhist nun; and the already mentioned Ruth, a writer who left behind her cosmopolitan life in New York City to inhabit an island on the fringes of the Western world. The novel juggles these narrative perspectives, as already made explicit in the table of contents, where chapters entitled "Nao" and "Ruth" rotate in all of the novel's parts. Nao and Ruth never meet in person, however; their encounter is linked to a material objectNao's diary-that "rode" the Pacific ocean's gyres to wash up on Ruth's island, miraculously intact. As she reads the diary, Ruth's imagination is increasingly affected by Nao's life; the novel intersperses Nao's diary (the "Nao" chapters) with third-person "Ruth" chapters focalized through Ruth and detailing her reactions to Nao's narrative. To borrow Edwin 
Hutchins's terminology, the diary is a "material anchor" for the abstract concept of gyre memory: it is a material prop that gives coherence to the plot and at the same time bridges the science of oceanic gyres with the human-scale language of narrative (for more on plot, the nonhuman, and material anchors, see Caracciolo, "Object-Oriented Plotting").

The diary is the lynchpin of the novel's interlaced form, which Ozeki interprets in a significantly different way from Powers's double narrative thread: while the two story lines of Orfeo eventually converge in the novel's ending, Nao's diary and Ruth's reading experiences remain separated by a temporal and geographical gulf. Put otherwise, the image-schematic form of A Tale for the Time Being is not the "fold" of narrative-musicalgenetic strands, but the gyre-like dance of two consciousnesses that chase one another while being denied the possibility of an embodied encounter. Ozeki develops the analogy between narrative and oceanic currents in a key scene from one of the "Ruth" chapters, in which the heterodiegetic narrator comments on news coverage from the tsunami that struck Japan in 2011. Ruth conjectures (based on suggestive, albeit not conclusive, evidence) that the tsunami swept Nao's diary into the ocean and took her life with it. In the plot, the earthquake that caused the tsunami-and the subsequent nuclear accident at Fukushimathus function as a dramatic irruption of nonhuman-scale climate and geology into the characters' lives. Considering the circulation of news stories about the tsunami on the Internet, the narrator wonders:

Is the Internet a kind of temporal gyre, sucking up stories, like geodrift, into its orbit? What is its gyre memory? How do we measure the half-life of its drift? The tidal wave, observed, collapses into tiny particles, each one containing a story: a mobile phone, ringing deep inside a mountain of 
sludge and debris; a ring of soldiers, bowing to a body they've flagged; a medical worker clad in full radiation hazmat, wanding a bare-faced baby who is squirming in his mother's arms; a line of toddlers, waiting quietly for their turn to be tested. (114)

Throughout this section of the novel, the focalization remains ambiguous: we don't know whether we should take these questions as the heterodiegetic narrator expressing Ruth's thoughts (as usually in the "Ruth" chapters), or as narratorial commentary. The indeterminate focalization heightens the complexity of the metaphorical language deployed in the passage. The immediate object of the narrator's comments are Internet photographs showing the catastrophic tsunami's aftermath. In a first analogical layer, these images-and the objects and situations that they depict (the mobile phone, the soldiers, etc.)-are seen as "containing a story": they overflow with the narratives of the people affected by the natural disaster. But the narrator goes one step further, drawing a parallel between the Internet that mediates these images - and these inchoate stories-and a rapidly rotating "gyre." This analogy involves an implicit equation between narrative and the waste that makes up the enormous garbage patches in the Pacific Ocean: as the text spells out on the same page, like "plastic confetti, [these images/stories are] drawn into the gyre's becalmed center, the garbage patch of history and time. The gyre's memory is all the stuff that we've forgotten" (114). Narratives, the narrator is suggesting, are discarded like garbage in the Internet age, and with them the many lives entangled in those stories. Ozeki's novel resists narrative's tendency to sink into digital oblivion: it singles out a material object dispersed in the ocean's memory (Nao's diary), unpacking its experiential significance for Nao and tracing its impact on Ruth's life. In this way, the novel demonstrates the incredible wealth of human experiences that are forgotten in the "garbage patch of history and time" - while 
simultaneously pointing up through formal means the interrelation between those experiences and material, nonhuman realities.

The gyre thus serves a double function in the novel's thematic system-with both functions taking on a distinctive image-schematic form: it hints at the unexpected interpersonal LINKAGE that nonhuman processes (such as natural disasters or oceanic currents) can establish across great geographical distances; at the same time, the gyre offers a template for understanding the CYCLE of material objects in a world whose spatio-temporal scale transcends individual life. Ozeki's novel is full of circles, after all: Oliver's hand gestures as he attempts to explain the movement of the oceanic gyres, children "[skipping] around ... in a circle" (103) in a Japanese game, a Jungle Crow native to Japan which somehow lands on Ruth's island and "[circles] the roof of [Ruth and Oliver's] house" (173), the "little round circle" of the hands' position in Zen meditation (181), and of course the cycle of Buddhist reincarnation itself. These patterns, evoked at the micro-textual level, link the levels of reality probed by the novel, from the animal to the human domain to the large-scale natural processes investigated by science. Moreover, the patterning of human-nonhuman entanglement also offers a key to the formal orchestration of the novel's plot, with its constant rotation of sections from Nao's diary and Ruth-focalized chapters. Via this shared circular patterning, narrative structure translates a scientific model into the human-scale experiences of characters who never meet but are united by the material effects of the Pacific Ocean's vortex-like movement.

Just as in Powers's novel, the abstraction of form is what brings these stylistic, thematic, and narratological levels of analysis together, and what the novel-ultimately-foregrounds: Oliver "could see time unfolding here, and history, embedded in the whorls and fractal forms 
of nature, and he would come home, sweating and breathless, and tell her what he'd seen" (60). The forms of nature are directly mapped onto the forms of the human body ("sweating and breathless"), and subsequently onto the forms of storytelling ("tell her what he'd seen"). Ozeki's novel attempts this formal translation by way of both analogical metaphors and imagistic plot structures, embodied patterns that hover between the nonhuman world and the quotidian realities of story.

\section{Conclusion}

The human scale may seem ideally positioned between the microcosm (for instance, DNA structure) and large-scale phenomena (for instance, the climate), but on a closer look this positioning is merely an illusion-an anthropocentric fallacy with deep roots in human evolutionary history and in the embodiment of mind. As recent work in cognitive science persuasively shows (see, e.g., Gibbs), this fallacy results from the close coupling between our cognitive faculties and our bodily make-up, which prompts us to see as metaphysically privileged the slice of reality that is commensurate with our bodies. I have argued in this article that, in the context of narrative, form is central to the encounter between this human-scale world and scientific models of more-than-human realities. This encounter takes place in formal terms, because science itself makes use of formal devices - both analogical and imagistic - as it abstracts from the physical world. I drew attention to two formal patterns traced by narrative; both function analogically: the patterning of metaphorical clusters, with its intrinsic directionality; and the imagistic contour of plot, which is both a matter of textual progression and an affective structure in readers' responses to narrative. When thematically bound up with scientific concepts, these formal devices enable narrative 
to overcome what Monika Fludernik has called its "anthropomorphic bias" (13), exposing the constitutive entanglement between human-scale reality and nonhuman phenomena.

Two broader lessons can be drawn from this argument, and they will also provide an agenda for future research. As narrative theory moves "beyond the human," to quote David Herman, it will have to refine its understanding of how the fundamental categories of narrative-and narrative theory-rely on the human body and mind. This focus on embodiment is necessary to explain how specific narratives may, through their formal sophistication, put pressure on basic human-scale categories and offer templates for understanding what is not immediately given in everyday experience (see also Caracciolo, "Posthuman Narration"). The narrative strategies examined in this article have important ramifications for science communication, an area in which researchers have been highlighting the great potential of narrative for shaping people's perception of scientific issues, including the current ecological crisis (see Dahlstrom). Moreover, I have mentioned the movement of New Formalism and its recognition of a fundamental continuity between aesthetic and socio-cultural forms. As a field that, like it or not, has never completely disowned its formalist roots, narrative theory should not miss the opportunity of making an intervention in that area, by extending and enriching the New Formalist project. The formal dialogue between narrative and science that I have traced in this article is a step in that direction.

\section{Works Cited}

Booth, Wayne C. The Rhetoric of Fiction. Chicago: Univ. of Chicago Press, 1983.

Caracciolo, Marco, Andrei lonescu, and Ruben Fransoo. “Metaphorical Patterns in Anthropocene Fiction." Language and Literature, under review. 
Caracciolo, Marco. “Object-Oriented Plotting and Non-Human Realities in DeLillo's

Underworld and Iñárritu's Babel." In Ecocriticism and Narrative Theory: Essays at a Critical Confluence, edited by Erin James and Eric Morel. Columbus: The Ohio State Univ. Press, under review.

---. “Posthuman Narration as a Test Bed for Experientiality: The Case of Kurt Vonnegut's Galápagos." Partial Answers 16, no. 2 (2018): 303-14.

Chakrabarty, Dipesh. "The Climate of History: Four Theses." Critical Inquiry 35, no. 2 (2009): 197-222.

Clark, Timothy. Ecocriticism on the Edge: The Anthropocene as a Threshold Concept. London: Bloomsbury, 2015.

Crutzen, Paul J. "Geology of Mankind.” Nature 415, no. 6867 (2002): 23.

Dahlstrom, Michael F. “Using Narratives and Storytelling to Communicate Science with Nonexpert Audiences." Proceedings of the National Academy of Sciences 111, no. 4 (2014): 13614-20.

Darwin, Charles. On the Origin of Species. New York: Norton, 1970.

Dissanayake, Ellen. "Prelinguistic and Preliterate Substrates of Poetic Narrative." Poetics Today 32, no. 1 (2011): 55-79.

Evans, Vyvyan, and Melanie Green. Cognitive Linguistics: An Introduction. Edinburgh: Edinburgh Univ. Press, 2006.

Fludernik, Monika. Towards a "Natural" Narratology. London: Routledge, 1996.

Fortin, Marc André. “Rivka Galchen's Atmospheric Disturbances: A Meteorology of the Mind." Configurations 24, no. 4 (2016): 533-52.

Galchen, Rivka. Atmospheric Disturbances. New York: Farrar, Straus, and Giroux, 2008. 
Gibbs, Raymond W. Embodiment and Cognitive Science. Cambridge: Cambridge Univ. Press, 2005.

Gibson, James J. The Senses Considered as Perceptual Systems. Westport, CT: Greenwood Press, 1983.

Grady, Joseph E. "Image Schemas and Perception: Refining the Definition." In From Perception to Meaning: Image Schemas in Cognitive Linguistics, edited by Beate Hampe and Joseph E. Grady, 35-56. Berlin: De Gruyter, 2005.

Grusin, Richard, ed. The Nonhuman Turn. Minneapolis: Univ. of Minnesota Press, 2015.

Hane, Carl E., Robert B. Wilhelmson, and Tzvi Gal-Chen. "Retrieval of Thermodynamic Variables within Deep Convective Clouds: Experiments in Three Dimensions." Monthly Weather Review 109, no. 3 (1981): 564-76.

Herman, David. "Narratology beyond the Human.” DIEGESIS 3, no. 2 (2014). https://www.diegesis.uni-wuppertal.de/index.php/diegesis/article/view/165.

Hogan, Patrick Colm. Affective Narratology: The Emotional Structure of Stories. Lincoln: Univ. of Nebraska Press, 2011.

Holt, Jim. "Orfeo, by Richard Powers." The New York Times, 10 Jan. 2014. https://www.nytimes.com/2014/01/12/books/review/orfeo-by-richard-powers.html. Hutchins, Edwin. "Material Anchors for Conceptual Blends." Journal of Pragmatics 37, no. 10 (2005): 1555-77.

James, Erin. The Storyworld Accord: Econarratology and Postcolonial Narratives. Lincoln: Univ. of Nebraska Press, 2015.

Johnson, Mark. The Body in the Mind. Chicago: Univ. of Chicago Press, 1987.

Kimmel, Michael. “Analyzing Image Schemas in Literature." Cognitive Semiotics 5 (2009): $159-188$. 
Kukkonen, Karin. "Plot." The Living Handbook of Narratology, edited by Hühn Peter.

Hamburg: Hamburg Univ. Press, 2014. http://www.lhn.unihamburg. de/article/plot.

Lakoff, George. Women, Fire, and Dangerous Things: What Our Categories Reveal about the Mind. Chicago: Univ. of Chicago Press, 1987.

Lakoff, George, and Mark Johnson. Metaphors We Live By. Chicago: Univ. of Chicago Press, 1980.

Levine, Caroline. Forms: Whole, Rhythm, Hierarchy, Network. Princeton, NJ: Princeton Univ. Press, 2015.

Levinson, Marjorie. “What Is New Formalism?” PMLA 122, no. 2 (2007): 558-69.

Morton, Timothy. The Ecological Thought. Cambridge, MA: Harvard Univ. Press, 2010.

Nersessian, Nancy. "How Do Scientists Think? Capturing the Dynamics of Conceptual Change in Science." In Cognitive Models of Science, edited by Ronald Giere, 3-45.

Minneapolis: Univ. of Minnesota Press, 1992.

Old, Chris, and Keith Haines. "North Atlantic Subtropical Mode Waters and Ocean Memory in HadCM3." Journal of Climate 19, no. 7 (2006): 1126-48.

Ortony, Andrew, ed. Metaphor and Thought. Cambridge: Cambridge Univ. Press, 1979.

Ozeki, Ruth. A Tale for the Time Being. London: Penguin, 2013.

Phelan, James. "Estranging Unreliability, Bonding Unreliability, and the Ethics of Lolita." Narrative 15, no. 2 (2007): 222-38.

---. Experiencing Fiction: Judgments, Progressions, and the Rhetorical Theory of Narrative. Columbus: The Ohio State Univ. Press, 2007.

Popova, Yanna. Stories, Meaning, and Experience. London: Routledge, 2015.

Powers, Richard. Orfeo. New York: Norton, 2014. 
Reagan, Andrew J., et al. "The Emotional Arcs of Stories Are Dominated by Six Basic Shapes." EPJ Data Science 5, no. 31 (2016). doi:10.1140/epjds/s13688-016-0093-1.

Rohrer, Tim. "Embodiment and Experientialism." In The Oxford Handbook of Cognitive Linguistics, edited by Dirk Geeraerts and Hubert Cuyckens, 25-47. Oxford: Oxford Univ. Press, 2007.

Ryan, Marie-Laure. Possible Worlds, Artificial Intelligence, and Narrative Theory. Bloomington: Indiana Univ. Press, 1991.

Schmitt, Arnaud. "Knots, Story Lines, and Hermeneutical Lines: A Case Study." Storyworlds 6, no. 2 (2014): 75-91.

Semino, Elena. Metaphor in Discourse. Cambridge: Cambridge Univ. Press, 2008.

Tan, Ed S. Emotion and the Structure of Narrative Film: Film as an Emotion Machine. Mahwah, NJ: Lawrence Erlbaum, 1996.

Trexler, Adam. Anthropocene Fictions: The Novel in a Time of Climate Change. Charlottesville: Univ. of Virginia Press, 2015.

Velleman, J. David. "Narrative Explanation." The Philosophical Review 112, no. 1 (2003): 125.

Woods, Derek. "Scale Critique for the Anthropocene." Minnesota Review 83 (2014): 133-42. 